\title{
EFICACIA HORIZONTAL DE LAS REGLAS DE COMPETENCIA JUDICIAL INTERNACIONAL EN EL REGLAMENTO No 1215/2012 (OBSERVACIONES AL HILO DE UNA CUESTIÓN PREJUDICIAL RETIRADA)
}

\author{
HORIZONTAL EFFECT OF THE RULES ON INTERNATIONAL \\ JURISDICTION IN REGULATION NO 1215/2012 (NOTES ON A \\ WITHDRAWN REQUEST FOR A PRELIMINARY RULING)
}

\author{
Marta RequeJo IsIDRo \\ Letrada del Tribunal de Justicia de la Unión Europea*
}

Recibido: 13.12.2020 / Aceptado: 11.01.2021

DOI: https://doi.org/10.20318/cdt.2021.5972

\begin{abstract}
Resumen: En diciembre de 2019 la Court of Appeal de Inglaterra y Gales solicitó al Tribunal de Justicia una decisión prejudicial sobre si el artículo 4, apartado 1, del Reglamento $n^{\circ} 1215 / 2012$, crea, a favor de las personas domiciliadas en Estados miembros, un derecho directamente exigible frente a otro particular; para el caso de respuesta afirmativa, preguntaba acerca de su tutela. La cuestión fue posteriormente retirada. En este texto se proponen argumentos para llegar a la solución que presumiblemente, a juicio del autor, habría sido la del Tribunal de Justicia. Se sugiere que, en ciertos casos, no es imposible una lectura distinta de ciertas disposiciones del Reglamento, que puede, además, ser oportuna para reforzar la protección de personas con domicilio en la Unión, y asegurar la aplicación efectiva de políticas legislativas esenciales.

Palabras clave: competencia judicial internacional, derechos individuales, tutela judicial efectiva, anti-suit injunctions, protección de la parte débil, protección de políticas legislativas esenciales, Estados miembros de la Unión, Estados terceros.
\end{abstract}

Abstract: In December 2019, the Court of Appeal of England and Wales requested the Court of Justice to decide whether Article 4 (1) of Regulation 1215/2012, confers a directly enforceable right upon a person domiciled in a Member State. For the case of a positive answer, it asked as well about remedies. The request was withdrawn later. This paper addresses what in all likelihood, according to the author, would have been the answer of the Court of Justice. It also submits that, under specific circumstances, a different reading of certain provisions of the Regulation might be possible, as well as suitable to reinforce the protection of persons domiciled in the European Union and to ensure the enforcement of essential legislative policies.

Keywords: international jurisdiction, individual rights, remedies, anti-suit injunctions, protection of the weaker party, safeguard of essential policies, EU Member States, third States.

Sumario: I. Introducción. II. Hechos y argumentos para la cuestión prejudicial. III. El precedente: contrato individual de trabajo, trabajador domiciliado en la Unión, y demanda en un tercer Estado 1. Samengo-Turner v J\&H Marsch \& McLennan (Services) Ltd. 2. Petter v EMC Europe Ltd. 3. ¿Derechos y obligaciones inter partes en la sección 5 del Reglamento? IV. Derechos dotados de eficacia horizontal en el Reglamento $n^{\circ} 1215 / 2012$. 1. Planteamiento. 2. El Reglamento $n^{\circ}$

*Las opiniones vertidas son exclusivas del autor y no representan las del Tribunal de Justicia. 
1215/2012 en clave de derechos subjetivos de los litigantes. A) La intención legislativa. Finalidad de las normas. B) Derechos y obligaciones en la jurisprudencia del Tribunal de Justicia. C) Un derecho subjetivo desprovisto de la tutela esencial. 3. En particular: el artículo 4, apartado 1, del Reglamento $\mathrm{n}^{\mathrm{o}}$ 1215/2012. A) La historia. B) Literalidad del precepto. C) Objeto y finalidad de la norma, y lugar en el sistema V. Demanda ante los órganos jurisdiccionales de un Estado tercero. VI. Excepcionalmente, ¿otra lectura?. 1. Un derecho de las partes débiles, dotado de eficacia horizontal mediata en la Unión. 2. Un derecho de las partes débiles, canal para el respeto de otras reglas. A) Las reglas de competencia como garantía de reglas de fondo. B) Tutela del derecho vulnerado en un Estado tercero a través de una anti-suit injunction. VII. Conclusión.

\section{Introducción}

1. A un mes escaso de la fecha prevista para la retirada del Reino Unido de la Unión Europea y el comienzo del período transitorio, la Court of Appeal de Inglaterra y Gales solicitó al Tribunal de Justicia la interpretación del artículo 4, apartado 1, del Reglamento (UE) n. ${ }^{\circ} 1215 / 2012^{1}$. A través del reenvío prejudicial, el tribunal inglés preguntaba si dicho precepto establece, a favor de las personas domiciliadas en la Unión Europea, un derecho a ser demandadas ante los órganos jurisdiccionales del Estado miembro de su domicilio, del que derive un derecho a no ser demandadas en un Estado tercero.

2. Para el caso de respuesta afirmativa, el Tribunal de Justicia debería decidir si la tutela de tal derecho exige adoptar una "anti-suit injunction" contra el demandante en un procedimiento abierto en el Estado tercero; y si es relevante, para contestar a esta pregunta, cómo afecte la orden conminatoria a la garantía de los derechos de su destinatario para el supuesto de que quisiera plantear el litigio sobre el fondo en la Unión.

3. La cuestión prejudicial fue retirada en septiembre de este año: las partes del procedimiento principal alcanzaron un acuerdo que puso fin al litigio $^{2}$. No es menos interesante por ello. Un discurso en términos de "derechos" y "obligaciones" de los particulares, con origen en las reglas de competencia del Reglamento $\mathrm{n}^{\circ}$ 1215/2012 o los instrumentos previos, es extraño (aunque no completamente ausente) en la jurisprudencia del Tribunal de Justicia, que interpreta las normas desde 1976, y ajeno a los ordenamientos de los Estados miembros.

4. Por otra parte, si el Tribunal de Justicia ha tenido ocasión de pronunciarse sobre las medidas "anti-suit" al hilo de la interpretación de los instrumentos previos al Reglamento $n^{\circ} 1215 / 2012^{3}$, no las ha examinado nunca desde la perspectiva que propone el órgano de reenvío. Tampoco la sentencia $O w u s u^{4}$, sobre la aplicación del Convenio de Bruselas en situaciones de procesos paralelos en un Estado miembro y un Estado tercero, ofrece una respuesta inmediata a lo que ahora se pregunta. El rechazo a las "anti-suit injunctions" se ha matizado en algunos Estados miembros en las últimas décadas, precisamente cuando el Reino Unido, su cuna por excelencia ${ }^{5}$, abandona la Unión Europea y queda abierta la puerta a que sus tribunales las adopten contra demandantes en procesos abiertos en la Unión ${ }^{6}$.

\footnotetext{
${ }^{1}$ Reglamento del Parlamento Europeo y del Consejo, de 12 de diciembre de 2012, relativo a la competencia judicial, el reconocimiento y la ejecución de resoluciones judiciales en materia civil y mercantil (refundición) (DO 2012, L 351, p. 1).

${ }^{2}$ Auto del Tribunal de Justicia de 25 de septiembre de 2020 (EU:C:2020:788).

${ }^{3}$ El Convenio de Bruselas, de 27 de septiembre de 1968, relativo a la competencia judicial y a la ejecución de resoluciones judiciales en materia civil y mercantil (DO 1972, L 299, p. 32), y el Reglamento del Consejo, de 22 de diciembre de 2000, relativo a la competencia judicial, el reconocimiento y la ejecución de resoluciones judiciales en materia civil y mercantil (DO 2000, L 12, p. 1). Las sentencias aludidas son las de 27 de abril de 2004, Turner (C-159/02, EU:C:2004:228); de 10 de febrero de 2009, Allianz y Generali Assicurazioni Generali (C185/07, EU:C:2009:69); y de 13 de mayo de 2015, Gazprom (C-536/13, EU:C:2015:316).

${ }^{4}$ STJUE de 1 de marzo de 2005, Owusu (C281/02, EU:C:2005:120).

${ }^{5}$ M. RequeJo Isidro, Proceso en el extranjero y medidas "antiproceso", De Conflictu Legum, Santiago de Compostela, 2000, para. 1-12.

${ }^{6}$ En la medida en que se siga la propuesta de volver al régimen de competencia judicial internacional y reconocimiento de decisiones preexistente al acceso del Reino Unido a la Unión Europea. En ese caso, las restricciones a la adopción de medidas anti-suit desaparecerían.
} 
5. Por todos estos motivos ha parecido oportuno dedicar algunas páginas a examinar la cuestión de la Court of Appeal, a pesar de que haya sido retirada.

\section{Hechos y argumentos para la cuestión prejudicial}

6. MG, con domicilio en el Reino Unido, y HH, domiciliado fuera de la Unión Europea desde principios de 2019, mantuvieron una relación sentimental entre 2013 y enero de 2019. En ese tiempo adquirieron valiosos activos muebles e inmuebles con el dinero de MG; algunos constan a nombre de ambos; otros, de MG o de HH en solitario; y otros, a nombre de sociedades bajo el control de HH. Tras el fin de la relación se planteó la cuestión de la propiedad de tales bienes.

7. El 25 de marzo de 2019, HH presentó una demanda ante la Family Court en Nueva Zelanda para que se procediera a la división de los bienes con arreglo a la Property (Relationships) Act 1976. Un día más tarde, MG presentaba una demanda contra HH ante la High Court of England and Wales, instando que declarase su propiedad sobre los activos. HH impugnó, sin éxito, la competencia judicial del tribunal inglés.

8. El 9 de abril de 2019, MG solicitó, en el marco del procedimiento inglés, una orden conminatoria prohibiendo a $\mathrm{HH}$ seguir adelante con el procedimiento neozelandés (esto es, una anti-suit injunction), argumentando que, a tenor del artículo 4, apartado 1, del Reglamento $n^{\circ} 1215 / 2012$, tenía derecho a ser demandada exclusivamente en Inglaterra. La solicitud fue denegada por sentencia de 23 de julio de 2019, en la que el juez declaró que las disposiciones del Reglamento $n^{\circ}$ 1215/2012 no exigen expresamente que el derecho de una persona domiciliada en la UE en virtud del artículo 4, apartado 1, del Reglamento se proteja a través de una orden "anti-suit".

9. MG interpuso recurso de apelación contra esta sentencia ante la Court of Appeal el 3 de diciembre de 2019, alegando, en apoyo de su solicitud, la redacción imperativa del artículo 4, apartado 1, del Reglamento ${ }^{\circ} 1215 / 2012$, y el énfasis en la seguridad jurídica que subyace al mismo. Se refirió también a la jurisprudencia del Tribunal de Justicia de la Unión Europea que describe el artículo 4, apartado 1, como una regla destinada a la protección de los demandados, e indica que las disposiciones del Reglamento confieren derechos e imponen obligaciones en las relaciones entre particulares. Finalmente, recordó los principios de eficacia y equivalencia del Derecho de la Unión en lo que respecta a las vías de recurso por vulneración de derechos derivados del Derecho de la Unión.

10. La interpretación de MG acerca del artículo 4, apartado 1, del Reglamento $n^{\circ} 1215 / 2012$, no convenció totalmente a la Court of Appeal, por los siguientes motivos: de entrada, la adopción de una "anti-suit injunction" en las circunstancias del caso impedirían a HH presentar su demanda al amparo de la Ley neozelandesa, ya que no podría ejercitar una acción similar en Inglaterra. En segundo lugar, el Reglamento no prevé expresamente una medida como la solicitada por MG, que, además, desconocen los ordenamientos de Derecho civil. La Court of Appeal recordó, no obstante, que si bien el Derecho de la Unión no permite a los tribunales de los Estados miembros adoptar "anti-suit injunctions" a fin de que una persona inicie procedimientos ante los tribunales de otros Estados miembros, la demanda de HH no involucra a uno de estos Estados, sino a un tercero.

11. Las dudas de la Court of Appeal se justifican, en fin, en una comparación entre el artículo 4, apartado 1, y el artículo 22, apartado 1, del Reglamento, relativo a la protección de los trabajadores, que ella misma ha interpretado en el pasado en el sentido de que crea un derecho a favor del trabajador, en tanto que parte débil. ${ }^{7}$

\footnotetext{
${ }^{7}$ Véase el apartado siguiente.
} 
12. Inseguro, en definitiva, sobre cómo proceder, el órgano jurisdiccional inglés elevó al Tribunal de Justicia las siguientes cuestiones prejudiciales:

(1) ¿Confiere el artículo 4, apartado 1, del Reglamento (UE) n. ${ }^{\circ}$ 1215/2012 a una persona domiciliada en un Estado miembro un derecho directamente exigible?

(2) Si la respuesta es afirmativa:

En caso de que se vulnere dicho derecho al iniciarse un procedimiento contra esa persona en un tercer Estado, ¿existe una obligación del Estado miembro de proporcionar una vía de recurso, incluida la concesión de una "anti-suit injunction"?

¿Se extiende dicha obligación a un caso en el que la acción ejercitable ante los tribunales de un tercer Estado no resulta ejercitable en virtud de la legislación aplicable en los tribunales del Estado miembro?

\section{El precedente: contrato individual de trabajo, trabajador domiciliado en la UE, y demanda en un tercer Estado}

13. Gray v Hurley no es el primer caso de solicitud de una anti-suit injunction ante tribunales ingleses con apoyo en el sistema Bruselas. Existen - o han trascendido- al menos dos ocasiones previas. En ambas la respuesta del juez de instancia fue negativa; la Court of Appeal revocó las decisiones y concedió las medidas ${ }^{8}$.

\section{Samengo-Turner v J\&H Marsch \& McLennan (Services) Ltd ${ }^{9}$}

14. En 2007, la Court of Appeal adoptó una decisión en el marco del recurso de tres trabajadores contra la negativa, en la instancia previa, de conceder una orden anti-suit tendente a impedir a los empleadores iniciar procedimientos en Nueva York. Los demandantes, con domicilio en Inglaterra, habían sido contratados como corredores de reaseguros por el primer demandado (MSL), una compañía inglesa y parte del grupo Marsh McLennan de compañías (el grupo MM). El tercer demandado (MMC), cuya sede se encuentra en Nueva York, es la sociedad holding de la que forma parte también el segundo demandado (GC). Los contratos de trabajo incluían un acuerdo sobre la elegibilidad para una bonificación anual en efectivo; este último se hallaba sujeto al Derecho de Nueva York, y se acompañaba de una cláusula de elección de foro, exclusiva, a favor de los tribunales del mismo Estado. Los demandantes, que viven en Inglaterra, trabajaron en el mercado de Londres para GC y su compañía inglesa asociada especializada en reaseguro facultativo.

15. En abril de 2007, los demandantes notificaron a MSL su voluntad de rescindir sus contratos de trabajo y comunicaron su intención de trabajar para uno de los competidores del grupo MM. El procedimiento de Nueva York, incoado por GC y MMC, comenzó un mes después: se debatía el derecho de los demandantes a retener el incentivo, en tanto que supeditado a la condición de no participar en actividades que pudieran ser perjudiciales para la empresa.

16. En este contexto, tras contestar infructuosamente la competencia del tribunal estadounidense, los trabajadores solicitaron en el Reino Unido una declaración afirmando la competencia de los

\footnotetext{
${ }^{8}$ Las decisiones han recibido en general comentarios negativos, ya entre la doctrina inglesa: C.M. Clarkson, J. HiLl, The Conflict of Laws, OUP, 4 ed., p. 156, siguiendo a A. BRIGGs, "Who is bound by the Brussels Regulation" LMCLQ, 2007, pp. 433-438; A. Dickinson, "Resurgence of the anti-suit injunction: the Brussels I Regulation as a source of civil obligations?", International \& Comparative Law Quarterly, 2008, pp. 465-473; I. BERGSON, “A new frontier for Brussels I- private law remedies for breach of the Regulation”, Journal of Private International Law, 2017, pp. 356-385.

${ }^{9}$ Samengo-Turner v Marsh \& McLennan (Services) Ltd [2007] EWCA Civ 723; [2007] 2 All ER (Comm) 813.
} 
tribunales locales. Pidieron también una orden judicial de alcance mundial contra la parte demandante en EEUU, basada en que el proceso de Nueva York recae sobre aspectos relacionados con los contratos de trabajo individuales de los demandantes y ha sido iniciado por su empleador. Por estos motivos se aplicaban, a su entender, las disposiciones de la sección 5 del Reglamento del Consejo 44/2001, que exigen que tales procedimientos se entablen únicamente en los tribunales de su domicilio.

17. El juez de instancia no estuvo de acuerdo. A la pregunta sobre si los demandantes tenían derecho a no ser demandados en Nueva York por incumplimiento del acuerdo de bonificación respondió en sentido negativo: el procedimiento de Nueva York no se refería a contratos de trabajo individuales; el acuerdo de bonificación no era un contrato de trabajo al carecer de las características propias de tales contratos, i.e., la obligación mutua de proporcionar y realizar trabajo a cambio de una remuneración adecuada. Añadió que MSL, que sería, a su juicio, el empleador de los demandantes, no era quien había iniciado el procedimiento en Nueva York. Por todo ello, el artículo 20 (1) del Reglamento no se aplicaba.

18. El tribunal de apelación sostuvo la opinión contraria. Apoyándose en los términos del acuerdo sobre incentivos concluyó su carácter inseparable respecto al contrato de trabajo mismo, que lo hace merecedor de la misma calificación. Sobre si los demandantes en Nueva York eran o no empleadores, la Court of Appeal optó por evitar una aproximación formalista; a partir de ahí derivó la legitimación de MMC y GC para demandar como si fueran empleadores de la amplia definición de "la empresa" en el acuerdo de bonificación. Añadió que MSL, que también estaría cubierto por la misma definición, solo podría haber presentado una demanda en Inglaterra para hacer cumplir los términos del empleo de los demandantes. Como empresas dentro del mismo grupo, MMC y GC tenían un interés económico en los contratos y su ejecución, y debían estar sujetos a la misma restricción jurisdiccional que $\mathrm{MSL}^{10}$.

19. La Court of Appeal continuó señalando que la interpretación propuesta para la sección 5 corresponde a los objetivos del Reglamento europeo de certeza y de evitar la multiplicidad de procedimientos: todas aquellas empresas del grupo MM que desearan demandar en los términos del acuerdo de bonificación estarían obligadas a hacerlo ante los tribunales del domicilio de los empleados. De lo contrario, MMC y cualquier otra empresa del grupo MM podrían demandar en Nueva York y MSL tendría que demandar en Inglaterra. Por otra parte, los tribunales ingleses presentaban la conexión más estrecha con la disputa en lo relativo a las actividades de los demandantes durante su empleo y la recepción del laudo en Inglaterra. Subrayó que tal construcción también ofrecía a los demandantes protección frente a procedimientos en jurisdicciones distintas a la de su domicilio.

20. La aplicabilidad de la sección 5 permitió al tribunal de apelación negar la validez de la cláusula de elección de foro a favor de los tribunales de Nueva York, por cuanto se había pactado antes de cualquier litigio.

21. Habida cuenta del fracaso de la impugnación de competencia por parte de los trabajadores en Nueva York, la Court of Appeal estimó que una indemnización por daños no sería un remedio suficiente, y que una anti-suit injunction estaba justificada, como única forma de dar efecto al Reglamento. ${ }^{11}$

\footnotetext{
${ }^{10}$ Esta construcción tampoco traspasa el velo corporativo de ninguna manera real. El Reglamento solo se ocupa de la asignación de competencias. El hecho de que MMC y GC deban ser tratados como empleadores para tales propósitos no significa que deban ser tratados así para cualquier otro propósito.

${ }^{11}$ La Court of Appeal valoró en su análisis, además del derecho del trabajador a ser, por ley, demandado en su domicilio, consideraciones de comity características a la hora de decidir sobre el pronunciamiento o no de una medida anti-suit. A este respecto, véase T. RAPHAEL, The Anti-Suit Injunction, OUP, 2008 (reedición 2012, revisión 2019), para. 50-64.
} 


\section{Petter v EMC Europe Ltd ${ }^{12}$}

22. La siguiente ocasión en la que una anti-suit injunction fue adoptada por la Court of Appeal presenta rasgos muy similares a los del asunto Samengo-Turner. El Sr. Petter trabajó en EMC Europe Ltd (EMC Europe), una empresa inglesa cuya matriz última es una empresa de Massachusetts, EMC Corporation (EMC), desde 2009, en calidad de Director de Cuentas Globales. Como tal, se le consideraba un empleado importante del que se podía esperar que hiciera una contribución significativa al éxito del negocio general de EMC. Con el fin de recompensar y alentar a dichos empleados, EMC operaba un esquema de distribución de acciones en virtud del cual las adjudicaciones de acciones ordinarias de EMC estaban disponibles para ellos en forma diferida. El valor de tales premios podría ser sustancial y en los años inmediatamente anteriores a su salida de EMC Europa formaron una parte significativa de la remuneración total del Sr. Petter.

23. A principios de 2015, el Sr. Petter decidió dejar EMC Europe y empezar a trabajar en una sucursal de otra empresa estadounidense, competidora de EMC. El 15 de enero de 2015 notificó a EMC Europe su intención de dimitir y comenzó a trabajar en la nueva empresa el 16 de febrero de 2015. El 27 de febrero de 2015 EMC inició un proceso contra el Sr. Petter en Massachusetts para solicitar una declaración en el sentido de que, según los términos del plan de acciones y los acuerdos relacionados, tenía derecho a rescindir las adjudicaciones de acciones más recientes realizadas a favor del Sr. Petter.

24. El Sr. Petter respondió iniciando un procedimiento contra EMC y EMC Europa en el Reino Unido, pidiendo, entre otros, una orden judicial provisional que prohibiera a EMC continuar con los procedimientos en su contra en Massachusetts. Tras recibir la notificación del procedimiento, EMC impugnó la jurisdicción del tribunal inglés con el argumento de que los contratos entre ella y el Sr. Petter, en virtud de los cuales se habían adjudicado acciones a este último, contenían una elección expresa de la ley de Massachusetts y un acuerdo de jurisdicción exclusiva a favor de los tribunales de dicho Estado. El tribunal estimó que el acuerdo de elección de foro era contrario a la sección 5 del Reglamento $\mathrm{n}^{\circ}$ 1215/2012 y, por tanto, inválido. Denegó, no obstante, la orden anti-suit solicitada, argumentando que la decisión de concederla o no es discrecional, y que en las circunstancias del caso el resultado no lograría, posiblemente, evitar el curso del procedimiento en el extranjero. Habría, pues, finalmente, dos decisiones incompatibles cuya ejecución las partes afectadas tratarían de evitar, con bastantes probabilidades de éxito. El juez expresó además su convicción de que, en vista de la incompatibilidad general entre el Reglamento y las medidas anti-suit, otorgarlas con apoyo en aquel texto es, por principio, inapropiado, excepto si existe un acuerdo de elección de foro entre las partes.

25. El Sr. Petter apeló. Como en Samengo-Turner, la Court of Appeal procedió en primer lugar a determinar si la relación entre el Sr. Petter y EMC y EMC, fundamentada en el acuerdo sobre recompensa en forma de acciones, es un contrato de trabajo, y las partes un "empleador" y un "trabajador" en el sentido de la sección 5 del Reglamento Bruselas I bis. Tras afirmarlo, pasó a analizar la cláusula de elección de foro a la luz de tal sección y concluyó que era nula. La orden anti-suit fue pronunciada, en gran medida, sobre la base de la similitud de los hechos en Samengo v Turner y el caso bajo examen.

\section{3. ¿Derechos y obligaciones inter partes en la sección 5 del Reglamento?}

26. Resulta de interés detenerse en este punto y preguntar qué argumentos condujeron a la Court of Appeal a afirmar la existencia de un derecho de eficacia horizontal del trabajador, y de una obligación correlativa que pesaría sobre el empleador, resultantes de la sección 5 del Reglamento.

${ }^{12}$ Petter v EMC Europe Ltd [2015] EWCA Civ 828; [2015] 2 CLC 178. 
27. La respuesta es, en realidad, bastante pobre. Como ha puesto de relieve la doctrina ${ }^{13}$, en Samengo v. Turner no se discutió la existencia del derecho; tampoco su naturaleza. Cuando, en Petter, Lord Justice Moore-Bick afirma que

"the existence of a right capable of protection by injunction"

es el fundamento de la decisión previa ${ }^{14}$, y añade, más adelante, que

"If it is necessary to spell out the principle which emerges from the judgment [Samengo-Turner] it is that in a case falling within Section 5 of the Regulation an anti-suit injunction should ordinarily be granted to restrain an employer from bringing proceedings outside the Member States in order to protect the employee's rights"

ignora que, en realidad, el tribunal se limitó a aceptar un dato sobre el que la opinión de las partes de aquel litigio coincidía ${ }^{15}$.

28. En consecuencia, la cuestión podría todavía haberse discutido con ocasión del asunto Petter; también, a la luz de la alusión directa del juez de instancia a que el Reglamento "crea obligaciones de naturaleza pública que vinculan a los órganos jurisdiccionales de los Estados miembros en sus decisiones sobre si son o no competentes, y no obligaciones y derechos de los litigantes cuyo respeto se puede imponer a través de órdenes imperativas" ${ }^{\prime \prime}$.

29. La discusión no tuvo lugar, pero ello no significa que la Court of Appeal desconociera la existencia de las dudas. De hecho, Lord Moore-Bick lo menciona expresamente

"Some commentators have suggested that the effect of Article 22(1) of the Regulation is to create rights of a public, rather than a private, nature which are not capable of being protected by injunction"17.

\section{Pero continúa, diciendo}

"However, no argument of that kind was addressed to us and it would in any event have been precluded by the decision in Samengo-Turner (...)"18.

31. Por su parte, Lord Sales, en su opinión concurrente a favor de otorgar la anti-suit injunction, elude cualquier referencia a un derecho del trabajador con origen en la sección 5 del Reglamento, prefiriendo una explicación en términos de orden público:

"In my view, section 5 of the Regulation reflects and seeks to give expression to a clear public policy to protect employees in relation to litigation relating to their employment, because they are taken to be in a weaker negotiating position by reason of their economic and social status as against employers. The decision in Samengo-Turner gives effect to this public policy, as reflected in the Regulation. In my opinion, it was legitimate for the court in Samengo-Turner to do this" ${ }^{\prime 19}$.

\footnotetext{
${ }^{13}$ I. Bergson, apartados 2 y 4.

${ }^{14}$ Petter, apartado 29.

${ }^{15}$ I. BergSon, loc. ult. cit., esp. p. 359, 362; y apartado 38 de Samengo-Turner.

${ }^{16}$ Petter, apartados 67 y 68.

${ }^{17}$ Samengo- Turner, apartado 29.

${ }_{18}$ Loc. ult. cit.

${ }^{19}$ Apartado 55. Lord Vos no cuestionó la realidad del derecho: véase el apartado 40, "That ratio [en Samengo-Turner] is, I think, that it is not open to the court to refuse an injunction where the overseas court cannot give and has not given effect to the Regulation, so that the only way to give effect to the English employee's statutory rights is to restrain the overseas proceedings" (cursiva añadida).
} 
32. Este hecho, unido a la observación de Lord Moore-Bick antes reproducida, indican que la Court of Appeal era consciente de la argumentación contraria al otorgamiento de una orden anti-suit con base en la sección 5 del Reglamento Bruselas I bis, y se sintió obligada a rechazarla. De ahí deriva que, en Inglaterra, se ha sentado un precedente ${ }^{20}$.

\section{Derechos dotados de eficacia horizontal en el Reglamento $n^{0} 1215 / 2012$}

\section{Planteamiento}

33. En el asunto C-943/16, el órgano jurisdiccional inglés solicitaba saber en primer lugar si el artículo 4 del Reglamento $\mathrm{n}^{\circ}$ 1215/2012 crea un derecho individual que un particular pueda invocar "horizontalmente", por oposición a un derecho frente al Estado, con eficacia "vertical", por vía de acción civil. El reenvío prejudicial se realizó en un contexto muy preciso: por una parte, no concurría más circunstancia atributiva de competencia a órganos jurisdiccionales en la Unión que el domicilio de la demandada, MG, en un Estado miembro; de ahí que la cuestión pudiera circunscribirse a un artículo del Reglamento. Por otra parte, la vulneración del (presunto) derecho de MG resultaría de plantear HH su demanda en un Estado tercero; ello no obstante, en su primera pregunta la Court of Appeal no distingue entre este caso y el de una demanda en la Unión.

34. En mi opinión, la respuesta a esta primera cuestión del órgano de reenvío es negativa - por lo que el Tribunal de Justicia no tendría que abordar ya la segunda. Los argumentos se encuentran, en primer término, en la historia y los fundamentos del sistema: si se quiere, en su ADN; responder a la Court of Appeal en este asunto obliga a un recorrido por terreno familiar a cualquier internacional-privatista en Europa. La interpretación sistemática del precepto y la literal también abogan por descartar que confiera un derecho subjetivo a no ser demandado fuera del domicilio en la Unión.

35. En principio, esta conclusión es la misma para la generalidad de los foros del Reglamento $n^{\circ}$ 1215/2012. Debo indicar, no obstante, ya ahora, que no descarto la posibilidad de una lectura distinta, o la oportunidad de una solución diferente, en algún caso. Desarrollaré esta opinión en la última parte del texto; ello me conducirá a ocuparme de la segunda cuestión planteada por el tribunal de apelación inglés en el asunto C-946/19, $M G$.

\section{El Reglamento $n^{0} 1215 / 2012$ en clave de derechos subjetivos de los litigantes}

36. Como hiciera primero el Convenio de Bruselas, y luego el Reglamento $n^{\circ} 44 / 2001$, el Reglamento actualmente en vigor proporciona el marco procesal básico para la tutela en la Unión de los derechos sustantivos de los particulares en situaciones transfronterizas, en materia civil y mercantil. $\mathrm{Su}$ capítulo II reparte la competencia judicial internacional entre los Estados miembros, y coordina el ejercicio de su jurisdicción respectiva ${ }^{21}$.

37. Una lectura del Reglamento $n^{\circ} 1215 / 2012$ más allá de esta función, en clave de derechos individuales entre las partes en el proceso, no parece verosímil. De entrada, exige identificar una intención legislativa -la de conferir derechos a los particulares, no frente al poder público, sino directamente entre sí- que es extraña a la concepción original del instrumento; su evolución posterior no lo desmiente (apartado A). En segundo término, la interpretación propuesta es ajena a la jurisprudencia constante del Tribunal de Justicia sobre el Convenio de Bruselas y los Reglamentos, y su apoyo en los principios

\footnotetext{
${ }^{20}$ I. Bergson, p. 363, p. 372.

${ }^{21}$ Véanse, por ejemplo, las STJUE de 11 de enero de 1990, Dumez France y Tracoba (C220/88, EU:C:1990:8), apartado 16; de 8 de mayo de 2019, Kerr (C25/18, EU:C:2019:376), apartado 21; de 6 de diciembre de 1994, Tatry (C406/92, EU:C:1994:400), apartado 55.
} 
generales vigentes en los sistemas jurídicos de los Estados miembros de la Unión sigue siendo limitado (apartado B). Encuentra, en fin, difícil encaje en un sistema que, basado en la confianza mutua entre las autoridades de los Estados miembros, ha rechazado expresamente las medidas anti-suit (apartado C).

\section{A. La intención legislativa. Finalidad de las normas}

38. El Reglamento en vigor, lo mismo que el Reglamento $n^{\circ} 44 / 2001$, encuentran sus raíces en el Convenio de Bruselas de 16 de septiembre de 1968. El paso del Convenio a los Reglamentos no alteró ni la estructura ni el fundamento esenciales del sistema; también se han mantenido muchas de las soluciones, entre ellas la que consagra el actual artículo 4, apartado 1. Por este motivo la intención legislativa debe buscarse ya en el texto convencional ${ }^{22}$.

39. El Tratado constitutivo de la Comunidad Económica Europea, firmado en Roma el 25 de marzo de 1957, no comprendía disposiciones relativas a la tutela de los derechos subjetivos nacidos de relaciones jurídico-privadas transfronterizas. Solo el artículo 220, cuarto guión, abordaba un aspecto de la cuestión, encargando a los Estados miembros entablar negociaciones entre ellos con vistas a garantizar, a favor de sus nacionales, la simplificación de las formalidades a que están sometidos el reconocimiento y la ejecución recíprocos de las decisiones judiciales.

40. El Convenio de Bruselas de 16 de septiembre de 1968, celebrado al amparo de aquella norma, llevó a la práctica su mandato, pero no se limitó al mismo: de haberse atenido estrictamente a lo ordenado solo habría suprimido las exigencias de traducción, legalización, y para la transmisión de documentos, propias del exequátur ${ }^{23}$. Tomando conciencia de las posibilidades de la integración europea, los negociadores concibieron ya entonces la idea de una libre circulación de las resoluciones judiciales ${ }^{24}$, cuya realización exigía unificar las condiciones de fondo relativas a los efectos de la decisiones. Con este fin, el Convenio incluyó una lista con criterios de competencia que se estimaron razonables para fundamentar la "regularidad internacional" de una decisión judicia ${ }^{25}$. El compromiso de los Estados partes en el Convenio de aplicar dichos criterios permitió eliminar el control de la competencia del juez de origen de la fase de reconocimiento o exequátur, con carácter general.

41. Los expertos se decidieron por el principio de la aplicación de oficio del Convenio, dándole expresión formal, en particular, en sus artículos 19 y $20^{26}$. En su interpretación del texto, el Tribunal de Justicia confirmó el objeto de las reglas y su naturaleza imperativa, e identificó a los órganos jurisdiccionales de los Estados miembros como sus destinatarios ${ }^{27}$.

42. Conforme a los trabajos explicativos del Convenio no hubo en ningún momento discusión sobre el otorgamiento, a través de sus disposiciones, de derechos subjetivos de una parte en el litigio

\footnotetext{
${ }^{22}$ Se plantea la pregunta sobre cómo llevar a cabo la reconstrucción de la intención legislativa original en el Convenio de Bruselas. He utilizado para ello los documentos publicados -los Informes a las sucesivas versiones; las Propuestas de la Comisión y de los Informes de la Comisión de Asuntos Jurídicos del Parlamento-, y, como argumento de autoridad, el texto de G.A.L. Droz, La Compétence judiciaire et l'effet des jugements dans la Communauté Economique Européenne selon la Convention de Bruxelles du 27 septembre 1968, Dalloz, 1972, que asistió a las negociaciones del Convenio como representante de la Conferencia de La Haya.

${ }^{23}$ G.A.L. Droz, loc. cit., pp. 8-9, siguiendo a M. Bellet.

${ }^{24}$ Informe sobre el Convenio de 27 de septiembre de 1968, relativo a la competencia judicial y a la ejecución de resoluciones judiciales en materia civil y mercantil (DO 1979, C 59, p. 1; en lo sucesivo "Informe JENARD”), p. 128.

${ }^{25}$ En palabras de G.A.L. Droz, loc. cit., p. 9.

${ }^{26}$ Informe JenARD, p. 130.

${ }^{27}$ STJUE de 16 de junio de 1981, Klomps (166/80, EU:C:1981:137), apartado 7: “el Convenio de Bruselas contiene en su Título II disposiciones que regulan de manera directa y detallada la competencia de los Tribunales del Estado de origen [...]. Estas disposiciones, obligatorias para el Juez de origen [...]”.
} 
contra la otra ${ }^{28}$. Este silencio no sorprende en lo relativo a la primera versión del Convenio: en primer lugar, como no ha dejado de destacar la doctrina, porque, en tanto que instrumento internacional absolutamente tradicional, generó derechos y obligaciones entre los Estados firmantes, y no entre particulares $^{29}$. En segundo término, ya es sabido que el Convenio se basó "en la existencia de una cultura jurídica común, en gran medida, a los Estados originarios de la Comunidad Económica Europea" ${ }^{\text {30 }}$. La idea de un derecho subjetivo a no ser demandado en el extranjero era ajena a sus tradiciones jurídicas ${ }^{31}$ (lo era también, por ende, la de cualquier medida destinada a protegerlo ${ }^{32}$ ), tanto desde una perspectiva procesal, como de Derecho internacional privado. Es cierto que, superadas las teorías iusprivatistas sobre el proceso, algunas de las restantes no descartaban explicarlo como relación jurídica triangular: del juez y las partes, y de las partes entre sí. Ahora bien, la idea de derechos subjetivos entre las partes con origen en las reglas sobre competencia judicial internacional era completamente extraña a estas concepciones, como lo era y es, en general, todavía, la de que la violación de las reglas procesales justifica por sí sola un derecho a indemnización de un litigante frente al otro.

43. De mayor interés es la falta de debate al hilo de la segunda versión del Convenio, a raíz del ingreso en la CEE de Dinamarca, Irlanda y el Reino Unido en 1972. El Convenio se extendió entonces a dos países pertenecientes a la tradición de common law, cuya forma de comprender la administración de justicia en el ámbito civil era muy diferente de los Estados miembros originales. La adhesión de estos países al instrumento obligó a reconsiderar varios aspectos del texto, atendiendo a características distintivas de los ordenamientos jurídicos de los nuevos Estados miembros ${ }^{33}$. En el marco de las negociaciones para la reforma del Convenio sí se valoró (y descartó) la doctrina, típica del common law, del "fórum non conveniens", que posibilita resoluciones discrecionales de un tribunal a propósito del ejercicio de su competencia internacional ${ }^{34}$. No consta que hubiera, en cambio, debate alguno a propósito de las antisuit injunctions, que funcionalmente cabe considerar como equivalentes a aquella doctrina ${ }^{35}$.

44. Los posteriores ingresos en la Comunidad Económica de Grecia, en 1981, los Reinos de España y Portugal en 1986, y Austria, Finlandia y Suecia en 1995, no originaron cambios ni en los principios, ni en la estructura esencial del Convenio, al que debieron adherirse todos estos países.

45. El Tratado de Amsterdam ${ }^{36}$ condujo a la adopción del Reglamento ${ }^{0}$ 44/2001, como medida para un espacio de libertad, seguridad y justicia donde esté garantizada la libre circulación de

\footnotetext{
${ }^{28} \mathrm{Ni}$ siquiera en relación con las normas de competencia tendentes proteger a determinadas categorías de personas por "consideraciones de orden social" (Informe JENARD, p. 148), o al privilegio que el Protocolo al Convenio preveía en su artículo 1 a favor de las personas domiciliadas en Luxemburgo, en relación con el artículo 5, apartado 1 (hoy, artículo 7, apartado 1). Su defensa se articulaba en el propio instrumento en forma de impugnación por el demandado, o de control de oficio, en caso de que no compareciera ante el juez.

${ }^{29}$ A. Dickinson, p. 470.

${ }^{30}$ Informe sobre el Convenio de 9 de octubre de 1978, relativo a la adhesión de Dinamarca, Irlanda y el Reino Unido (DO 1979, C 59, p. 184; en lo que sigue, "Informe SCHLOSSER"), punto 16.

${ }^{31}$ Sobre un "derecho a no ser demandado en el extranjero", en la época de la celebración del Convenio, solo se conoce en el continente un supuesto, cuya base, no obstante, se encuentra en el Derecho sustantivo - el § 1353 (1) BGB, sobre derechos y deberes matrimoniales-: la sentencia del Reichtsgericht de 3 de marzo de 1938, 157 RGZ 136.

${ }^{32}$ Históricamente, la aparición de las órdenes conminatorias del tipo "anti-suit" está ligada al desarrollo de la equity en Inglaterra, de la mano de la Chancery Court, al lado de las reglas de common law que aplicaban otras jurisdicciones del reino. La posibilidad de que la Chancery Court llevara a buen término su labor requería poder paralizar el recurso a los otros tribunales, así como la ejecución de las decisiones que de ellos emanaran. Más adelante las medidas se extendieron a demandantes en procesos iniciados en Escocia, Irlanda y las colonias. En países de Derecho civil, en 1968 solo había trascendido un caso, en Alemania: véase la nota previa.

${ }^{33}$ Informe SCHLOSSER, punto 16.

${ }^{34}$ Informe Schlosser, puntos 76 y ss.

${ }^{35}$ Conclusiones del Abogado General D. Ruiz-Járabo Colomer, de 20 de noviembre de 2003, en el asunto Turner (C159/02, EU:C:2003:632), punto 38. La similitud se aprecia, en particular, en los supuestos de pluralidad actual o potencial de litigios sobre la misma causa.

${ }^{36}$ De 2 de octubre de 1998 (DO 1997, L 340, p. 1). Con él la adopción de medidas para la cooperación judicial en materia civil pasó a ser competencia comunitaria: véanse los artículos 61 y 65 TCE, hoy artículos 67 y 81 TFUE.
} 
personas $^{37}$. A tenor de su Preámbulo, el Reglamento debía asegurar la continuidad de los resultados obtenidos con el Convenio ${ }^{38}$. El Reglamento ${ }^{\circ} 1215 / 2012$, al amparo del artículo 81 del TFUE ${ }^{39}$, refunde el Reglamento $n^{\circ} 44 / 2001$ al objeto de "mejorar la aplicación de algunas disposiciones, facilitar en mayor medida la libre circulación de las resoluciones judiciales y mejorar el acceso a la justicia" ${ }^{40}$. La continuidad con los instrumentos previos en la interpretación y aplicación de las disposiciones que retomen las de aquellos es la regla ${ }^{41}$.

46. La finalidad de las reglas de competencia - distribuirla entre los distintos Estados miembros de modo uniforme y ordenado- no fue objeto de análisis en el marco de las negociaciones de ninguno de los reglamentos. No se planteó que tales reglas tuvieran aptitud para otra cosa, con la excepción, al hilo de la refundición del Reglamento $n^{\circ} 44 / 2001$, relativa al domicilio del demandado, cuya función de criterio general de aplicabilidad general del Reglamento sí dio lugar a debate: su supresión, que no prosperó, tendría por objetivo mejorar el acceso a la justicia en la Unión.

47. Por su parte, la protección procesal de determinados particulares considerados "partes débiles", que impide que puedan ser demandados ante órganos jurisdiccionales de Estados diferentes al de su domicilio, sí fue considerada de cara a la refundición del Reglamento $n^{\circ} 44 / 2001$. Ahora bien, no se habló en ningún momento de derechos individuales a no ser demandados en otros lugares en la Unión, o fuera de ella. Se examinó y mejoró la posición jurídica de estas partes, en cambio, en tanto que demandantes, si tienen su domicilio en la Unión.

48. De los informes nacionales realizados por encargo de la Comisión relativos a la aplicación del Reglamento $n^{\circ} 44 / 2001$ en los Estados miembros, de cara a la revisión del instrumento, se desprende aún la falta de familiaridad o, incluso, la intolerancia, en relación con medidas inter partes asociadas a la vulneración por una de ellas de las reglas de competencia ${ }^{42}$.

\section{B. Derechos y obligaciones en la jurisprudencia del Tribunal de Justicia}

49. Un discurso en términos de "derechos" y "obligaciones" entre los particulares en litigio, con origen en las reglas de competencia del Reglamento $\mathrm{n}^{\mathrm{o}}$ 1215/2012 o los instrumentos previos, es extraño a la jurisprudencia del Tribunal de Justicia, que los interpreta desde $1976^{43}$. Es legítimo entender esta ausencia como una indicio fuerte de que las reglas atributivas de competencia judicial internacional no confieren derechos con eficacia inter partes, ni imponen obligaciones correlativas ${ }^{44}$.

50. Siendo justos, hay que decir que la expresión "derechos y obligaciones" sí aparece en algunas decisiones del Tribunal de Justicia. Lo hace, no obstante, casi exclusivamente al hilo de la justificación de la interpretación autónoma del Reglamento, disociada de disposiciones concretas, en lo que se ha convertido en una fórmula de estilo que no sugiere, por lo demás, que se trate de derechos u obligaciones entre las partes litigantes: la expresión típica es, "con miras a asegurar, en la medida de lo posible,

\footnotetext{
${ }^{37}$ Considerando primero.

${ }^{38}$ Considerando quinto.

${ }^{39}$ Tratado de Funcionamiento de la Unión Europea, de 13 de diciembre de 2007 (DO 2007, L 306, p. 1; versión consolidada DO 2016, C 202, p. 47).

${ }^{40}$ Considerando primero.

${ }^{41}$ Considerando trigésimo cuarto del Reglamento ${ }^{\circ}$ 1215/2012, y jurisprudencia constante del Tribunal de Justicia: véase, recientemente, la STJUE de 24 de noviembre de 2020, Wikingerhof (C-59/19, EU:C:2020:950) apartado 20.

${ }^{42}$ Tal como recoge N. Andrews, Civil Processes, CUP, 2013, vol. II, para. 10.49 y ss.

${ }^{43}$ La primera sentencia data de 6 de octubre de 1976, Industrie Tessili Italiana Como (12/76, EU:C:1976:133).

${ }^{44}$ En este sentido, I. Bergson, en nota al pie 78, subraya la diferencia con decisiones en otras materias, en las que el Tribunal de Justicia se refiere claramente a derechos subjetivos de los particulares.
} 
la igualdad y la uniformidad de los derechos y obligaciones que resultan del Reglamento Bruselas I para los Estados miembros y las personas interesadas" ${ }^{\prime 4}$.

51. Excepcionalmente, en el marco de secciones especiales del Reglamento, el Tribunal alude a un "derecho" a entablar una acción ante los tribunales de determinado Estado, o a un "privilegio jurisdiccional", cuyo objeto es proteger al litigante "débil" ". En ningún momento indica que se trate de una posición cualificada que quepa hacer valer por vía de acción contra la otra parte ${ }^{47}$. Al menos hasta hoy, no cabe decir algo diferente tampoco en relación con ningún otro precepto, en particular con el artículo 25 , sobre cláusulas de elección de foro. La idea de un derecho a no ser demandado fuera del lugar pactado sí aparece, en cambio, en una decisión del Tribunal de la EFTA, donde la premisa - esto es, que el acuerdo es creador de tal derecho - no se discute ${ }^{48}$.

52. La falta de referencia a derechos y obligaciones de los particulares con efecto horizontal es coherente con una interpretación del Reglamento $n^{\circ}$ 1215/2012 realizada a la luz de los cánones habituales, y sumando los principios generales que se deducen del conjunto de los sistemas jurídicos nacionales:

- La génesis del documento ya ha sido explicada, y con ella, su objetivo de ordenar el ejercicio de la jurisdicción de los Estados miembros a través de reglas de competencia uniforme.

- Desde un punto de vista sistemático, el instrumento pertenece al conjunto de los elaborados al amparo del artículo 81, apartado 2 TFUE, para la cooperación judicial, a los que es también ajena, como norma, la creación de derechos y obligaciones entre los particulares ${ }^{49}$.

- En cuanto al texto, dejando a un lado ahora el del artículo 4 - su redacción fue uno de los argumentos de MG en la disputa ligada al asunto C-943/16, por lo abordo luego-, y con el caveat de que las diferencias lingüísticas en este punto son aptas desde luego para restar valor al argumento literal, cabe subrayar que expresiones del tenor "las personas (...) solo podrán ser demandadas" $"$, que tal vez cabría entender como indicativas de una relación horizontal entre las partes ${ }^{51}$, coexisten con otras como "En materia de (...), se determinará la competencia con arreglo a las disposiciones de la presente sección" ${ }^{52}$, donde es claro que es

${ }^{45}$ Por ejemplo, entre otras muchas, sentencias de 23 de octubre de 2014, flyLAL-Lithuanian Airlines (C302/13, EU:C:2014:2319) apartado 24; de 22 de octubre de 2015, Aannemingsbedrijf Aertssen y Aertssen Terrassements (C523/14, EU:C:2015:722) apartado 20; de 7 de julio de 2016, Lebek (C70/15, EU:C:2016:524), apartado 32.

${ }^{46}$ Por ejemplo, en las sentencias de 21 de junio de 1978, Bertrand (150/77, EU:C:1978:137), apartados 11 y 21 ; de 13 de julio de 2000, Group Josi (C412/98, EU:C:2000:399), apartado 39; de 17 de septiembre de 2009, Vorarlberger Gebietskrankenkasse (C347/08, EU:C:2009:561), apartado 31.

${ }^{47} \mathrm{Si}$ bien es cierto que tampoco ha indicado lo contrario. Sobre este punto véase infra, bajo el apartado VI.

${ }^{48}$ STJUE de 25 de abril de 2012, Granville Establishment, as. E-13/11. Estaba en juego el carácter discriminatorio de una disposición de la ley procesal de Liechtenstein conforme a la cual los requisitos formales de las cláusulas de elección de foro son distintos según que la elección recaiga sobre tribunales locales, o remita a una jurisdicción extranjera.

${ }^{49}$ La búsqueda de la expresión "derechos y obligaciones" en la interpretación de otros instrumentos por el Tribunal de Justicia, referida al contenido de los mismos, arroja un resultado prácticamente nulo. La STJUE de 22 de noviembre de 2018, ZSE Energia a.s (C-627/17, EU:C:2018:941), sobre el Reglamento n ${ }^{\circ}$ 861/2007 del Parlamento Europeo y del Consejo, de 11 de julio de 2007, por el que se establece un proceso europeo de escasa cuantía (DO 2007, L 199, p. 1), la emplea en su apartado 26 al definir el concepto de "parte", para negar que lo sean terceros como, por ejemplo, una parte coadyuvante. Pueden encontrarse excepciones: el $n^{\circ}$ Reglamento (UE) n ${ }^{\circ}$ 655/2014 del Parlamento Europeo y del Consejo, de 15 de mayo de 2014, por el que se establece el procedimiento relativo a la orden europea de retención de cuentas a fin de simplificar el cobro transfronterizo de deudas en materia civil y mercantil (DO 2014, L 189, p. 59), crea un derecho de indemnización de una parte frente a la otra, como mecanismo para lograr el adecuado equilibrio entre acreedor y deudor y evitar el uso abusivo de la orden de retención (considerando décimo noveno y artículo 13).

${ }^{50}$ Artículo 5, apartado 1. En los artículos 7 y 8 se lee "Una persona domiciliada en un Estado miembro [también] podrá ser demandada".

${ }^{51}$ Quizá, más que de derechos y obligaciones, habría que hablar de privilegios e inmunidades, usando la taxonomía ya clásica de W. N. Hohfeld, “Some Fundamental Legal Conceptions as Applied in Judicial Reasoning”, Yale Law Journal, 2013, pp. 16-59.

${ }^{52}$ Esta fórmula introduce las secciones 3, 4 y 5 del capítulo II. Véase también el artículo 6, apartado 1. 
objeto de las reglas regir la competencia judicial internacional. Cabe defender, por lo tanto, que se trata de expresiones intercambiables ${ }^{53}$.

53. Finalmente, esta es la única interpretación compatible con los principios generales derivados del conjunto de los ordenamientos de los veintisiete Estados miembros de la Unión. Aun admitiendo que el rol de estos principios como elemento de la interpretación autónoma de los instrumentos de Derecho procesal civil europeo es incierto - aparecen y desaparecen del discurso del Tribunal de Justicia sin mayor explicación ${ }^{54}$-, en un caso como este, donde el posicionamiento general es prácticamente unívoco, traerlos a colación es ajustado. Con el Reino Unido fuera de la Unión Europea, un derecho a no ser demandado en el extranjero derivado de una norma procesal es desconocido en los Estados miembros, incluso cuando las mismas partes han limitado por acuerdo sus posibilidades de litigar a un determinado foro. En las decisiones recientes ${ }^{55}$ que han adoptado medidas equivalentes a las anti-suit injunctions en Francia y en Alemania en relación con demandas planteadas en un Estado tercero, el fundamento es sustantivo, y no procesal ${ }^{56}$. Sobre la acción para reclamar lo pagado en concepto de defensa legal por violación de un acuerdo de elección de foro, en Estados miembros de tradición civilista se ha admitido solo últimamente, tras un proceso entablado en un Estado no miembro, con apoyo en argumentos sustantivos $^{57}$; en otras palabras, la vulneración de la norma procesal no sustenta la acción por daños de una parte frente a la otra.

\section{Un derecho subjetivo desprovisto de la tutela esencial}

54. La interpretación de las reglas de competencia judicial del Reglamento como creadoras de derechos subjetivos del demandado (los derechos subjetivos como la "otra cara de la moneda" de tales reglas $^{58}$ ) tropieza con un obstáculo radical: la tutela natural de tales derechos a través de órdenes de no incoar, o no persistir en una acción judicial en determinado foro en la Unión, es incompatible con el fundamento del sistema, y con el modus operandi que de él deriva.

55. Como ha indicado el Tribunal de Justicia reiteradamente, el Convenio de Bruselas y los Reglamentos se basan en la confianza que los Estados contratantes otorgan mutuamente a sus sistemas jurídicos y a sus respectivas instituciones judiciales ${ }^{59}$. Inherente a ella es que las normas de competencia

\footnotetext{
${ }^{53}$ La ambigüedad de las reglas puede ser sin embargo un argumento para aventurar otra interpretación posible: véase infra, bajo el apartado VI.

${ }^{54}$ Ejemplos de utilización es la STJUE de 23 de octubre de 2014, flyLAL-Lithuanian Airlines (C302/13, EU:C:2014:2319), apartado 24, y recientemente, la de 7 de mayo de 2020, Rina (C641/18, EU:C:2020:349), apartado 30.

${ }^{55}$ En 2003, la Cour de Cassation francesa aprobó una decisión del Tribunal de Apelación de Versalles que prohibía a un acreedor individual iniciar un procedimiento de embargo de bienes del deudor quebrado en España, y ello, porque hacerlo pondría en riesgo el procedimiento (universal) de insolvencia en curso en Francia. La medida defiende, pues, un principio básico de la insolvencia. Véase Banque Worms c. Époux Brachot, Cour de Cassation, 1re chambre civile, de 19 de noviembre de 2002 (pourvoi $\left.\mathrm{n}^{\circ} 00-22.334\right)$.

${ }^{56}$ Se trató en todos los casos de medidas de reacción contra otra anti-suit, tendente a impedir el proceso ante un tribunal europeo. En Francia : In Zone Brands Europe, Cour de Cassation, Ire chambre civile, de 14 de octubre de 2019, (pourvoi 08-16369) ; Ordonnance du Président du TGI de Paris- RG n 19/59311, de 8 de noviembre de 2019; Cour d'Appel de Paris, Pôle 5, Chambre 16, de 3 de marzo de 2020. En Alemania : Landsgericht München, 11 de julio de 2019, 21 O 9333/19 (traducción inglesa no oficial aquí: https://www.katheraugenstein.com/wp-content/uploads/2019/12/EN-21-O-9333-19.pdf; para pronunciar la orden el tribunal argumentó un fundamento legal sustantivo, en el § 227 BGB); Oberlandesgericht München, 12 diciembre 2019, 6 U 5042/19, y nota de N. Kessler, C. Palzer, Mitteilungen der deutschen Patentanwälte, 2020, pp. 169-171. El tribunal apoyó la medida en la necesidad de defender al demandante en Alemania, contra quien se había dictado una anti-suit injunction en EEUU: a su juicio, esta última le impediría ejercitar su derecho, constitucionalmente protegido, a defender la patente ante los tribunales. Una traducción no oficial al inglés puede encontrarse aquí: http://eplaw.org/wp-content/ uploads/2019/12/DE-AASI-HRC-Munich-6-U-5042-19-EN.pdf.

${ }^{57} \mathrm{Al}$ amparo del $\S 280$ BGB: Sentencia del Bundesgerichthof de 17 de octubre de 2019 - III ZR 42/19.

${ }^{58}$ En expresión de J. SchröDER, "The right not to be sued abroad", en Festschrift für G. Kegel, Verlag W. Kohlhammer, 1987, p. 524.

${ }^{59}$ STJUE de 9 de diciembre de 2003, Gasser (C116/02, EU:C:2003:657), apartado 72.
} 
judicial internacional, comunes a todos los órganos jurisdiccionales de los Estados contratantes, puedan ser interpretadas y aplicadas con la misma autoridad por cada uno de $\operatorname{ellos}^{60}$. Una orden conminatoria del tipo "anti-suit" conlleva una valoración, por el juez de un Estado miembro, de la pertinencia de iniciar un procedimiento ante un órgano jurisdiccional de otro Estado miembro. Esta valoración es contraria al principio de confianza mutua y, por lo tanto, inadmisible. La orden es apta, además, para sustraer al juez ante el que se ha planteado la demanda la ocasión de realizar un examen de su propia competencia, a lo que viene obligado por el artículo 28 del Reglamento $n^{\circ} 1215 / 2012$, garantizando la protección del demandado que, domiciliado en un Estado miembro distinto, no comparezca. Este control es imperativo incluso si el demandado ha sido debidamente notificado, e independiente de su cualidad de parte débil. En la misma línea, el artículo 27.

56. Resulta de lo anterior que, en el seno de la Unión, el derecho a ser demandado en el propio domicilio, de existir, sería un derecho "sin dientes", en tanto que desprovisto del mecanismo esencial de protección. La falta de la garantía jurisdiccional típica habla en contra de entender que las reglas de competencia confieren al demandado un derecho subjetivo frente al actor ${ }^{61}$.

\section{En particular: el artículo 4, apartado 1, del Reglamento nº 1215/2012}

57. La primera disposición del capítulo II del Reglamento $n^{\circ}$ 1215/2012 es el artículo 4, apartado 1, que declara la sujeción de toda persona domiciliada en un Estado miembro a los órganos jurisdiccionales del mismo, sin perjuicio de otras previsiones del Reglamento. Los razonamientos que he expuesto para las reglas del capítulo II del Reglamento $n^{\circ}$ 1215/2012 se aplican también a este artículo: no presenta características que lo singularicen en el conjunto y permitan leer en él algo distinto (o adicional) a una norma sobre atribución de competencia ${ }^{62}$.

\section{A. La historia}

58. La incorporación al Convenio de Bruselas de una regla atributiva de competencia a los tribunales del domicilio del demandado no planteó dudas a los negociadores ${ }^{63}$. Se trataba de una solución reconocida en los seis primeros Estados miembros, así como en los veintisiete que, en la época, eran parte de la Conferencia de La Haya; y estaba consagrada, como regla de competencia indirecta, en los convenios existentes sobre reconocimiento y exequátur. Servía además a trasladar al ámbito internacional el adagio actor sequitur forum rei, generalizado en los procesos a nivel interno, en la convicción de que, si está justificado en este, encuentra aún mayor razón de ser en aquel ${ }^{64}$. En una de sus primeras decisiones sobre el Convenio, el Tribunal de Justicia explicó la regla en la preocupación por facilitar la

\footnotetext{
${ }^{60}$ Sentencias de 27 de junio de 1991, Overseas Union Insurance y otros (C351/89, EU:C:1991:279), apartado 23; Gasser apartado 48; y Turner, apartado 30.

${ }^{61}$ La cuestión de si otras formas de protección, en concreto una acción por daños, sería o no compatible con el sistema Bruselas, está aún por resolver. A mi juicio, una respuesta afirmativa requiere un análisis detenido, incluso cuando la regla de competencia en juego se base en el acuerdo entre las partes. Recuerdo en este sentido el argumento del Tribunal de Justicia en la sentencia de 10 de febrero de 2009, Allianz y Generali Assicurazioni Generali (C185/07, EU:C:2009:69), apartado 31, rechazando una orden anti-suit porque impide al demandante que considera que un acuerdo arbitral es nulo, ineficaz o inaplicable, el acceso al órgano jurisdiccional estatal ante el que hubiera acudido en virtud del Reglamento: de este modo se le priva de una forma de tutela judicial a la que tiene derecho. La posibilidad de verse condenado a indemnizar al demandado posee un potencial carácter disuasorio apto para producir el mismo efecto.

${ }^{62}$ Función que le reconocen por ejemplo las sentencias de 13 de julio de 2000, Group Josi (C412/98, EU:C:2000:399), apartado 39; de 17 de septiembre de 2009, Vorarlberger Gebietskrankenkasse (C347/08, EU:C:2009:561), apartado 31.

${ }^{63}$ G.A.L. Droz, p. 53; Informe JenARD, p. 139. Sí hubo discusión acerca de si sería preferible la residencia habitual (Informe JENARD, pp. 135 y ss): la filosofía subyacente - el favor al demandado- sería en cualquier caso la misma.

${ }^{64}$ Informe JENARD, p. 139: "Efectivamente, es más difícil, hablando en general, defenderse ante los tribunales de un país extranjero que ante los tribunales de otra ciudad en el país del domicilio".
} 
defensa al demandado, en "contrapartida a las facilidades que el Convenio establece para el reconocimiento y ejecución de resoluciones judiciales extranjeras" $"$.

59. Si la presencia de una preocupación por la "comodidad procesal" del demandado y su defensa no es discutible, nada en los trabajos relativos al Convenio en su primera versión o las subsecuentes, ni en sus preámbulos, apoya la hipótesis de que la (o una) finalidad del legislador fuera la de conferir al demandado domiciliado en un Estado miembro un derecho subjetivo frente al actor. El sistema contemplaba -como hace hoy- dos posibilidades al alcance del demandado frente a una acción planteada ante un tribunal incompetente, por no corresponder con su domicilio u otro de los foros del Convenio: comparecer e impugnar la competencia, en una lectura a contrario del artículo $18^{66}$; o no comparecer, en cuyo caso la garantía de que una persona con domicilio en otro Estado miembro solo sería demandada en alguno de los lugares previstos en el Convenio se encomendaba a los órganos jurisdiccionales en el artículo 20 del Convenio (el actual artículo 28 del Reglamento ${ }^{\circ}$ 1215/2012).

60. El contenido del artículo 2, apartado 1, del Convenio se ha mantenido inalterado a lo largo de las sucesivas versiones, así como en los Reglamentos, y no ha generado, en tanto que criterio de competencia, ninguna discusión particular.

\section{B. Literalidad del precepto}

61. En la argumentación de la Court of Appeal, la existencia de un derecho a no ser demandado fuera del Estado miembro del domicilio se sustenta, ante todo, en la redacción del artículo 4, apartado 1, del Reglamento $n^{\circ} 1215 / 2012$, que en inglés es como sigue: "Subject to this Regulation, persons domiciled in a Member State shall [...] be sued in the courts of that Member State" ${ }^{\prime 7}$.

62. Resulta a todas luces precipitado deducir obligaciones y derechos entre las partes en un litigio a partir del tenor de una versión lingüística de una regla ${ }^{68}$, y ello, porque puede suceder que no coincida en alguna otra. Esto es lo que sucede aquí: la dicción del artículo 4 en español no expresa un imperativo dirigido al demandante, sino la sujeción del demandado a los tribunales del Estado miembro de su domicilio ${ }^{69}$.

63. Se añade a lo anterior que, aunque pudiera pensarse a primera vista que el artículo 4, por su tenor, enuncia una obligación del actor - correlativamente, crea un derecho a favor del demandado- la opinión cambia al leer la norma en su integridad en cualquier idioma. El primer lugar, el apartado 1 del artículo 4 salva otras disposiciones del Reglamento, de conformidad con las cuales una persona domiciliada en un Estado miembro puede también ser demandada en otros, en determinadas circunstancias ${ }^{70}$.

${ }^{65}$ STJUE de 4 de julio de 1985, AS-Autoteile Service (C-220/84, EU:C:1985:302), apartado 15. Muy claras, las conclusiones del Abogado General Lenz presentadas en el mismo (no publicadas, EU:C:1985:246).

${ }^{66}$ Conforme al artículo 18 del Convenio, en el caso de demanda ante una jurisdicción incompetente, la comparecencia del demandado que no tuviera por objeto impugnar la competencia equivalía a una sumisión tácita.

${ }^{67}$ Énfasis añadido. En la misma línea, la versión portuguesa (,,[...] ]as pessoas domiciliadas num Estado-Membro devem ser demandadas [...] nos tribunais desse Estado-Membro“), o la alemana (,Vorbehaltlich der Vorschriften dieser Verordnung sind Personen, die ihren Wohnsitz im Hoheitsgebiet eines Mitgliedstaats haben, ohne Rücksicht auf ihre Staatsangehörigkeit vor den Gerichten dieses Mitgliedstaats zu verklagen“).

${ }^{68}$ Véase ya la STJUE de 12 de julio de 1979, Koschniske (C-9/79, EU:C:1979:201), apartado 6; y en el marco del Reglamento $\mathrm{n}^{\circ}$ 44/2001, entre otras, la de 17 de septiembre de 2009, Vorarlberger Gebietskrankenkasse (C347/08, EU:C:2009:561), apartado 26.

69 “"...] Las personas domiciliadas en un Estado miembro estarán sometidas, sea cual sea su nacionalidad, a los órganos jurisdiccionales de dicho Estado". Cerca, las versiones francesa e italiana: "[...] les personnes domiciliées sur le territoire d'un État membre sont attraites [...]"; "[...] le persone domiciliate nel territorio di un determinato Stato membro sono convenute [...]"

${ }^{70}$ Véase epígrafe siguiente, sobre la relación sistemática entre los foros, y la traducción en la práctica del carácter de principio del criterio que recoge el artículo 4, apartado 1. 
En segundo término, el apartado 1 del artículo 4 no es separable del apartado 2 del mismo artículo, que solo puede entenderse como instrucción destinada a los tribunales de los Estados miembros ${ }^{71}$ : la apariencia de un derecho de origen legal provocada por la norma es, en realidad, un espejismo ${ }^{72}$.

64. No existe, en fin, ningún pronunciamiento del Tribunal de Justicia a propósito del artículo 4, apartado 1, del Reglamento $\mathrm{n}^{\mathrm{O}} 1215 / 2012$, o de sus precedentes, que apunte a una comprensión del texto como fundamento de un derecho individual de las personas con domicilio en la Unión, en razón de su literalidad. La interpretación del artículo 4, apartado 1, no ha dado lugar a especiales dificultades; en las decisiones del Tribunal de Justicia el precepto es habitualmente, sin más, un referente sistemático que, como "regla" o "principio" sirve a delimitar el alcance de otros criterios, atributivos como él de competencia judicial internacional ${ }^{73}$.

\section{Objeto y finalidad de la norma, y lugar en el sistema}

65. El artículo 4, apartado 1, del Reglamento $n^{\circ}$ 1215/2012, sirve a la atribución de competencia judicial a órganos jurisdiccionales accesibles al demandado, con el fin de garantizar su derecho de defensa. El precepto traduce en su articulado el principio, recogido en el preámbulo, de que la competencia judicial se basa generalmente en el domicilio del demandado ${ }^{74}$. De ahí su relación con el resto de las reglas de competencia, que, en tanto que derogatorias del principio, son de excepción.

66. Una comprensión del artículo 4, apartado 1, en tanto que obligación del actor, y correlativamente, derecho del demandado, no es conciliable, sin embargo, con las posibilidades que abren a aquel, entre otros ${ }^{75}$, los foros de competencia especial. A lo largo de los años, el Tribunal de Justicia ha determinado la relación entre estos foros y el del domicilio del demandado: ha sentado una regla de alternatividad perfecta entre ellos, y reconocido al demandante, en exclusiva, la opción sobre dónde litigar ${ }^{76}$. La primacía del artículo 4, apartado 1, sobre los otros criterios de competencia se traduce exclusivamente en la interpretación estricta del alcance de estos últimos en relación con la Litis: a diferencia de ellos, el artículo 4, apartado 1, faculta al demandante para plantear todos los aspectos de su demanda ante un solo tribunal ${ }^{77}$.

67. La naturaleza de principio del artículo 4, apartado 1, no altera tampoco el juego normal de las reglas del Reglamento sobre litispendencia o conexidad ${ }^{78}$ : en caso de dualidad de procesos ante órganos jurisdiccionales de Estados miembros, prevalece el que ha sido llamado a conocer en primer lugar, y ello aunque la competencia del segundo se apoye en el foro del domicilio del demandado.

\footnotetext{
71 "Persons who are not nationals of the Member State in which they are domiciled shall be governed by the rules of jurisdiction applicable to nationals of that Member State". Este giro del texto es claro también en otros idiomas, a diferencia de lo que ocurre con el apartado 1 del artículo 4.

72 A. Dickinson, p. 471.

${ }^{73}$ Entre las sentencias más antiguas, véase la de 22 de noviembre de 1978, Somafer (33/78, EU:C:1978:205), apartado 7; entre las más recientes, la de 25 de enero de 2018, Schrems, (C498/16, EU:C:2018:37), apartado 43. Esto vale también cuando la competencia tiene carácter exclusivo: STJUE de 17 de diciembre de 2015, Komu y otros (C605 /14, EU:C:2015:833), apartado 24, y las que cita.

${ }^{74}$ Considerando décimo quinto.

${ }^{75}$ Otras posibilidades resultan de convenios internacionales entre los Estados miembros y Estados terceros: conforme al artículo 71, apartado 2, letra a), un Estado miembro que sea parte de un convenio sobre una materia especial pueda fundamentar su competencia en dicho convenio, aunque el demandado esté domiciliado en el territorio de un Estado miembro que no sea parte del mismo.

${ }^{76}$ La jurisprudencia es constante: sentencias de 30 de noviembre de 1976, Bier (21/76, EU:C:1976:166), apartado 11; de 26 de mayo de 1982, Ivenel (133/81, EU:C:1982:199), apartado 11; de 11 de enero de 1990, Dumez France y Tracoba (C220/88, EU:C:1990:8), apartado 17; de 7 de marzo de 1995, Shevill y otros (C-68/93, EU:C:1995:61) apartado 19; auto de 14 de noviembre de 2013, Krejci Lager \& Umschlagbetrieb (C469/12, EU:C:2013:788), apartado 20.

${ }^{77}$ STJUE de 27 de octubre de 1998, Réunion européenne y otros (C51/97, EU:C:1998:509), apartado 51.

${ }^{78}$ Artículos 29 y 30 . Compárese con el artículo 31, apartados 1 y 2, para el caso de la prórroga de competencia por virtud de una cláusula atributiva de competencia exclusiva a favor de un Estado miembro.
} 
68. La violación del artículo 4, apartado 1, del Reglamento, no justifica la denegación del reconocimiento y ejecución en otro Estado miembro de la decisión pronunciada, ni siquiera cuando el criterio de competencia en que se basó el juez de origen es uno de los exorbitantes ${ }^{79}$.

69. La trascendencia del domicilio del demandado como criterio de competencia es, en definitiva, relativa, lo que refuerza la opinión contraria a una comprensión de la norma como atributiva de un derecho (tampoco, de un privilegio ${ }^{80}$ ) individual a las personas con domicilio en la Unión a ser demandadas ante los tribunales de su domicilio.

\section{Demanda ante los órganos jurisdiccionales de un Estado tercero}

70. Mi opinión sobre la ausencia de derechos subjetivos resultantes de las reglas de competencia del Reglamento ${ }^{\circ} 1215 / 2012$, con carácter general; y de un derecho a ser demandado en el domicilio, derivado del artículo 4, apartado 1, en particular, no es, en principio, distinta cuando la acción contra el sujeto domiciliado en la Unión se plantea en un tercer Estado.

71. El Reglamento $n^{\circ} 1215 / 2012$ pertenece al conjunto de medidas que la Unión puede adoptar en el contexto de la cooperación judicial entre los Estados miembros, en particular cuando lo estima preciso para el buen funcionamiento del mercado interior ${ }^{81}$. Esta orientación funcional determinó la adopción del Convenio de Bruselas de $1968^{82}$, y se mantuvo en el Reglamento n ${ }^{\circ}$ 44/2001 ${ }^{83}$.

72. Es cierto que, en lo que respecta a su ámbito de aplicación territorial, el Reglamento no pretende unificar las reglas de competencia de los Estados miembros sólo para los litigios que se susciten dentro de la Unión. Situaciones con un elemento de extranjería que implique a Estados terceros son aptas para dar lugar a cuestiones sobre la competencia internacional de los órganos jurisdiccionales de Estados miembros, a las que el Reglamento debe aplicarse porque las disparidades entre las legislaciones nacionales existentes en la materia podrían crear obstáculos al funcionamiento del mercado interior ${ }^{84}$.

73. Estas consideraciones, que admiten "externalidades" del régimen de competencia judicial de la Unión, afectan exclusivamente a los órganos jurisdiccionales a los que este vincula ${ }^{85}$. No se trata, en definitiva, de imponer reglas de competencia sobre Estados no miembros (para lo que la Unión Europea sería, sobra decirlo, incompetente), ni de regular a través de ellas la conducta procesal de las personas en el extranjero.

\footnotetext{
${ }^{79}$ Artículo 45, apartado 3.

${ }^{80}$ Que se traduciría, por ejemplo, en una relación jerárquica entre el foro previsto en el artículo 4, apartado 1, y el artículo 7.

${ }^{81}$ Considerandos tercero, cuarto y quinto.

${ }^{82}$ Véase la Nota dirigida el 22 de octubre de 1959 por la Comisión de las Comunidades Europeas a los Estados miembros con objeto de invitarles a entablar negociaciones al amparo del artículo 220, cuarto guión, del TCE, reproducida en el Informe JENARD, p. 125.

${ }^{83}$ En el marco del objetivo más amplio, que expresa su considerando primero, de "mantener y desarrollar un espacio de libertad, de seguridad y de justicia en el que esté garantizada la libre circulación de personas".

${ }^{84}$ En relación con el Convenio de Bruselas, STJUE Owusu, apartado 34, y ya antes, la STJUE de 13 de julio de 2000, Group Josi (C412/98, EU:C:2000:399), sobre la irrelevancia del domicilio del demandante fuera de la UE; para el Reglamento $\mathrm{n}^{\mathrm{o}}$ 44/2001, STJUE de 19 de julio de 2012, Mahamdia (C154/11, EU:C:2012:491), apartado 33, apartado 66 y dispositivo. Véase también el Dictamen del Tribunal de Justicia 1/03, de 7 de febrero de 2006 (Competencia de la Comunidad para celebrar el nuevo Convenio de Lugano relativo a la competencia judicial, al reconocimiento y a la ejecución de resoluciones judiciales en materia civil y mercantil), (EU:C:2006:81), apartados 139 y ss.

${ }^{85}$ Los instrumentos europeos influyen también sobre la aplicación de las normas en convenios que vinculan a los Estados miembros con terceros Estados, que queda excluida si menoscaba los principios que inspiran la cooperación judicial en materia civil y mercantil en el seno de la Unión Europea: véase la STJUE de 4 de septiembre de 2014, Nickel \& Goeldner Spedition (C157/13, EU:C:2014:2145), apartado 38 y ss. Tal consecuencia, sin embargo, solo se impone sobre los Estados miembros de la Unión partes del Convenio de que se trate, y no sobre los demás contratantes.
} 
74. La preocupación por asegurar la tutela de los derechos en situaciones que involucraran a particulares vinculados a la Unión fue una cuestión de debate al hilo de la refundición del Reglamento $\mathrm{n}^{\mathrm{o}} 44 / 2001$. Ahora bien, se examinó con miras a ampliar el acceso a los tribunales de los Estados miembros $^{86}$, y no a impedir que fueran demandados en un Estado tercero ${ }^{87}$.

75. Existen, además, signos claros de que el Reglamento $n^{0} 1215 / 2012$ no protege a las personas domiciliadas en la Unión frente a eventuales demandas fuera de ella. Por el contrario, la posibilidad está implícitamente contemplada: lo demuestra que, como ya sucedía bajo el Convenio de Bruselas y el Reglamento $n^{\circ} 44 / 2001$, el reconocimiento y ejecución en un Estado miembro de una decisión dictada en otro puede ser bloqueada por inconciliabilidad con la resolución de un Estado tercero, relativa a las mismas partes en un litigio con el mismo objeto y la misma causa, que reúna las condiciones necesarias para su reconocimiento en el Estado miembro requerido ${ }^{88}$.

76. El artículo 33 del Reglamento n. ${ }^{\circ} 1215 / 2012$, sin parangón en los instrumentos previos, autoriza a los Estados miembros a suspender un procedimiento ante ellos si existe previamente una demanda pendiente ante un órgano jurisdiccional de un tercer Estado con el mismo objeto, la misma causa y las mismas partes. Esta facultad, que se completa con la obligación de poner fin al procedimiento si el órgano jurisdiccional extranjero alcanza una decisión susceptible de ser reconocida, no juega si la competencia del órgano de la Unión se basa en determinados criterios, entre los que no se encuentra el domicilio del demandado ${ }^{89}$.

77. Entiendo, a la luz de lo anterior, que el Reglamento $n^{\circ} 1215 / 2012$ no condena como tal el "fórum shopping", esto es, la búsqueda por el demandante de una competencia judicial internacional que resulte más favorable para sus pretensiones que el foro del domicilio del demandado, amparado en la falta de uniformidad jurídica de los sistemas de derecho internacional privado ${ }^{90}$.

\section{Excepcionalmente, ¿otra lectura?}

78. Indiqué al explicar mi planteamiento que no excluyo la posibilidad de una lectura distinta, o la oportunidad de una solución diferente a la expuesta en los epígrafes precedentes, en algún caso. Me

\footnotetext{
${ }^{86}$ La Comisión sugirió eliminar el requisito de domiciliación del demandado, extendiendo así el ámbito de aplicación del Reglamento: Propuesta de Reglamento del Parlamento Europeo y del Consejo relativo a la competencia judicial, el reconocimiento y la ejecución de resoluciones judiciales en materia civil y mercantil, $\operatorname{COM}(2010) 748, \mathrm{p}$. 3. No prosperó, excepto para las secciones dedicadas a contratos de consumo y trabajo: véanse los artículos 18, apartado 1, y 21, apartado 2.

${ }^{87}$ En realidad, el camino en este sentido es la vía convencional. La voluntad de extender la protección de personas domiciliadas en la Comunidad a otros países con vínculos particulares en el ámbito económico se plasmó en la celebración del Convenio de Lugano 16 de septiembre de 1988, relativo a la competencia judicial y a la ejecución de resoluciones judiciales en materia civil y mercantil (DO 1988, L 319, p. 9). Los Estados miembros han ratificado en nombre de la Unión convenios sobre competencia judicial para litigios con elementos transfronterizos (véase la Decisión del Consejo, de 4 de diciembre de 2014, relativa a la aprobación, en nombre de la Unión Europea, del Convenio de La Haya, de 30 de junio de 2005, sobre Acuerdos de Elección de Foro, DO 2014, L 353, p. 5). Hoy, la Unión se mantiene activa en el ámbito de las relaciones exteriores participando en las negociaciones de instrumentos internacionales.

${ }^{88}$ Artículo 45, apartado 1, letra d. Es indiferente que hayan sido dictadas contra un demandado domiciliado en la Unión, o fuera de ella.

${ }^{89} \mathrm{El}$ artículo 34 contempla una regla similar, aunque no idéntica, para demandas conexas.

${ }^{90}$ La solución es diferente en otros supuestos: por ejemplo, si existe desigualdad entre las partes de un litigio en relación con la defensa de sus intereses respectivos - véase la opinión del abogado general Ruiz-Járabo Colomer presentadas el 6 de septiembre de 2005 en el asunto Staubitz-Schreiber (C1/04, EU:C:2005:500), apartado 71 y ss, en relación con el artículo 3, apartado 1, primera frase, del Reglamento $\mathrm{n}^{\circ}$ 1346/2000, sobre procedimientos de insolvencia. El fórum shopping es también condenado a priori por razón de la materia: véase el considerando trigésimo del Reglamento (CE) n ${ }^{\circ} 6 / 2002$ del Consejo, de 12 de diciembre de 2001, sobre los dibujos y modelos comunitarios (DO 2002, L 3, p. 1). En la misma línea, el apartado VI a continuación.
} 
referiré en particular a aquel en que el demandado fuera de su domicilio es una parte débil en la relación jurídica (y, por ende, en el litigio) ${ }^{91}$.

\section{Un derecho de las "partes débiles", dotado de eficacia horizontal mediata en la Unión}

79. No es fácil defender que las disposiciones del capítulo II del Reglamento $n^{\circ} 1215 / 2012$ son algo más que reglas para la distribución de competencia. Y, sin embargo, he expuesto más atrás cómo el Tribunal de Justicia utiliza los términos "derechos" y "obligaciones" en relación con alguna de las secciones especiales, sin precisar frente a quién existe el derecho, o la obligación. Como explica la doctrina, cabría argumentar que el "derecho" es frente a la administración de justicia; más complicado es convencer de esto mismo en relación con la obligación ${ }^{92}$.

80. He señalado también que en estas secciones coexisten expresiones que parecen apuntar a una relación horizontal entre las partes, y otras que muestran como objeto de las reglas regir la competencia judicial internacional ${ }^{93}$. Sostener, como hice allí, que son intercambiables, no aclara en qué sentido: en otras palabras, tanto cabría decir que todas son, exclusivamente, reglas de competencia, como que todas son (son también) reglas sobre derechos y obligaciones entre las partes. Así cabe leer, en la sección 3, el artículo 14, apartado 1, sobre la acción del asegurador y del profesional frente a la parte débil: "la acción del asegurador solo podrá ser ejercitada ante los órganos jurisdiccionales del Estado miembro en cuyo territorio esté domiciliado el demandado (...)". Lo mismo, en la sección 4, el artículo 18, apartado 2: "La acción entablada contra el consumidor por la otra parte contratante solo podrá interponerse (...)"; y la referencia a la acción del empresario, en la sección 5: "Los empresarios solo podrán demandar a los trabajadores $(\ldots)$ ".

81. A la luz de lo anterior, no me parece de todo punto imposible argumentar - y concluir, como hizo la Court of Appeal inglesa en los asuntos Samengo-Turner y Petter ${ }^{94}$ - que, de forma excepcional, determinados preceptos del Reglamento $\mathrm{n}^{\circ} 1215 / 2012$ podrían ser, además de distributivos de la competencia judicial internacional entre los Estados miembros, atributivos de derechos a ciertos particulares. Que esta no fuera la intención original del Convenio de 1968, y no se encuentre tampoco en la negociación de los instrumentos que siguen, no es un obstáculo imposible de superar: todo texto ha de adaptarse a nuevas necesidades que aparecen con el transcurso del tiempo, so pena de ser derogado.

82. En el seno de la Unión Europea, entender que los artículos 14, apartado 2, 18, apartado 2, y 22, apartado 1, del Reglamento, confieren un derecho a la parte débil e imponen una obligación al profesional o empleador, es un paso que sigue sin trauma excesivo a la materialización (incorporación de valores materiales) de los foros de competencia. Ahora bien, desde el punto de vista de la tutela del derecho, si su infracción se produce en la Unión, no cambia nada: medidas del tipo anti-suit seguirían sin tener sitio en el sistema; y no es seguro que una garantía jurisdiccional a través de la acción por daños no sea incompatible con é ${ }^{95}$. En realidad, quizá haya que admitir que, en la Unión, los derechos subjetivos derivados de reglas de competencia, de existir, no reciben protección por medio de los mecanismos propios del tráfico jurídico privado, sino de forma mediata ${ }^{96}$ : el derecho se hace efectivo en las relaciones de los particulares a través de los órganos del Estado; desde esta perspectiva podrían explicarse el artículo 26,

\footnotetext{
${ }^{91}$ No significa que no puedan existir otros. La limitación a las secciones sobre partes débiles se debe sin más a que el punto de partida de las elucubraciones sobre el tema tienen su origen en las sentencias Samengo-Turner y Petters de la Cour of Appeal, a propósito de contratos de trabajo.

${ }^{92}$ Como indica también I. Bergson, p. 369.

${ }^{93}$ Supra, bajo el apartado IV, 2, B.

${ }^{94} \mathrm{Id}$. loc.

${ }^{95}$ Supra, nota al pie 61.

${ }^{96}$ Salvando las (notables) distancias, se trataría de una situación similar a la que describen las teorías de la mittelbare Drittwirkung y la asunción judicial para los derechos fundamentales.
} 
apartado 2, del Reglamento ${ }^{97}$, así como el mandato de denegar el reconocimiento o la ejecución, a petición de la parte interesada, en caso de conflicto entre una resolución y el capítulo II, secciones 3, 4 o 5, en el supuesto de que el demandado sea el tomador del seguro, el asegurado, un beneficiario del contrato de seguro, la persona perjudicada, el consumidor o el trabajador, a tenor del artículo 45, apartado 1, letra e, i).

\section{Un derecho de las "partes débiles", canal para el respeto de otras reglas}

\section{A. Las reglas de competencia como garantía de reglas de fondo}

83. En relación con demandas entabladas contra partes débiles fuera de la Unión Europea, entender que las disposiciones de las secciones 3, 4 y 5 del Reglamento ${ }^{\circ}$ 1215/2012 confieren derechos a una parte frente a la otra encuentra refuerzo en la exclusión de tales secciones de los artículos 33 y 34. Dicha lectura posee un valor añadido: es una fórmula para garantizar el respeto (por la vía de la aplicación) de normas materiales que lo reclaman para el ámbito internacional, incluso más allá de los límites geográficos de la Unión ${ }^{98}$; en tal circunstancia, debe ser un juez de la Unión el que conozca del pleito. Así pues, a través de criterios de competencia concebidos para relaciones en que una parte es estructuralmente débil no solo se daría protección procesal a dicha parte: se aseguraría además la aplicación de legislación material de la Unión informada igualmente por objetivos de protección u otros de interés general. Dado que el Reglamento no regula el (no)reconocimiento de decisiones procedentes de terceros Estados, no es posible articular desde él mismo una reacción contra una sentencia que atente contra aquellos objetivos. En este contexto, reconocer en la regla atributiva de competencia un derecho individual de la parte débil a no ser demandado en un Estado tercero contra el actor en dicha demanda, que se traduzca en la facultad de paralizar o poner fin al proceso allí entablado, sería una interpretación al servicio de la normativa sustantiva de la Unión ${ }^{99}$.

\section{B. Tutela del derecho vulnerado en un Estado tercero a través de una anti-suit injunction}

84. En el as. C-946/19, la Court of Appeal preguntaba si, para el caso de que el artículo 4 del Reglamento confiriera un derecho directamente exigible, y este fuera vulnerado por un procedimiento iniciado en un tercer Estado, existe una obligación de los Estados miembros de proporcionar un remedio, incluida la concesión de una anti-suit injunction. La cuestión vale también si se estima que el Reglamento $n^{\circ} 1215 / 2012$ crea un derecho a favor de las personas domiciliadas en Estados miembros, que las protege frente a ser demandas en un Estado tercero, en tanto que partes débiles.

85. La respuesta debe tener en cuenta lo que sigue:

- A falta de normativa uniforme corresponde a cada Estado miembro garantizar la salvaguarda de derechos que el Derecho de la Unión confiere a los justiciables, configurando el procedi-

\footnotetext{
${ }^{97}$ Conforme al cual "En las materias contempladas en las secciones 3, 4 o 5, si el demandado es el tomador del seguro, el asegurado, un beneficiario del contrato de seguro, la persona perjudicada, el consumidor o el trabajador, el órgano jurisdiccional se asegurará, antes de asumir la competencia en virtud del apartado 1, de que se ha informado al demandado de su derecho a impugnar la competencia del órgano jurisdiccional y de las consecuencias de comparecer o no".

${ }^{98}$ Dicho de otro modo, el objetivo regulatorio de la norma sustantiva no podrá lograrse, o no óptimamente, si no se acompaña tal norma de otras de procedimiento que garanticen su aplicación efectiva. En sectores donde el carácter transfronterizo de la actividad es la regla, y la norma material tiene vocación de aplicación (o de producir su efecto) extraterritorial, asegurar su eficacia pasa por acompañarla de criterios adaptados de competencia judicial internacional y para la determinación de la ley aplicable.

${ }^{99}$ No se trata de una proposición desconocida. Por ejemplo, en sus conclusiones de 11 de diciembre de 2014 en el as. C-352/13, CDC (EU:C:2014:2443), apartado 27, el abogado general Jääskinen defendía la idea de poner el Derecho procesal al servicio del material en relación con el artículo 101 TFUE, en el mercado interior. La analizo para la normativa europea de protección de datos personales en M. REQUEJo IsIDRo, "La aplicación privada del derecho para la protección de las personas físicas en materia de tratamiento de datos personales en el Reglamento (UE) 2016/679”, La Ley Mercantil, n 42 (diciembre), 2017 , p. 1.
} 
miento al efecto. La regulación procesal de esta tutela no debe ser menos favorable que la de los recursos semejantes establecidos para la protección de los derechos reconocidos por el ordenamiento jurídico interno (principio de equivalencia), ni hacer imposible en la práctica o excesivamente difícil el ejercicio de los derechos conferidos por el ordenamiento jurídico de la Unión (principio de efectividad) ${ }^{100}$.

- El objetivo del Reglamento $\mathrm{n}^{\circ}$ 1215/2012 no es la armonización de los Derechos procesales de los Estados miembros. Como indicó el Tribunal de Justicia muy pronto, tratándose de reglas procesales procede remitirse a las reglas nacionales del órgano jurisdiccional ${ }^{101}$; su aplicación no puede, sin embargo, menoscabar la eficacia del Reglamento ${ }^{102}$.

86. A la luz de lo que precede, cabe afirmar, a partir de la premisa de que existe un derecho a ser demandado en el propio domicilio en la Unión, que los Estados miembros deben proporcionar una vía de recurso en caso de vulneración consistente en plantear la demanda en un Estado tercero; y que es decisión de cada Estado miembro que tal vía consista en una anti-suit injunction, o se lleve a cabo de otra forma. En abstracto, no hay razones para pensar que la normativa nacional relativa a una anti-suit injunction no pueda ser aplicada en consonancia con los principios de equivalencia o efectividad. Tampoco, para pensar que una medida anti-suit pone en peligro el efecto útil del Reglamento $n^{\circ}$ 1215/2012. A diferencia de lo que sucedía en los asuntos resueltos por las sentencias Turner y Allianz, en el escenario presente la medida no estaría dirigida contra el demandante en un Estado miembro, por lo que no impedirá a los órganos jurisdiccionales de uno de ellos ejercer las competencias atribuidas en virtud del Reglamento ${ }^{103}$. Una medida anti-suit contra no afectaría tampoco a otras disposiciones del instrumento, obstaculizando su aplicación. Por lo que se refiere, en particular, a las relativas a litispendencia y conexidad previstas en los artículos 33 y 34 para situaciones que involucran a órganos jurisdiccionales de Estados miembros y de Estados terceros, son reglas facultativas, y además inaplicables si están en juego las secciones 3, 4 y 5 del Reglamento. Por este motivo, pronunciar la orden conminatoria no resulta incompatible con ellas ${ }^{104}$.

\section{Conclusión}

87. La pregunta sobre si del Reglamento $n^{\circ} 1215 / 2012$ se deriva un derecho a ser demandado en un determinado lugar no es banal. El acuerdo sobre el fondo entre Mandy Gray y Hamish Hurley, protagonistas del proceso que suscitó la cuestión prejudicial C-946/19, nos ha privado de obtener una respuesta (que se intuía, por lo demás, negativa). En las páginas precedentes he desarrollado argumentos en contra de una lectura de las reglas de competencia judicial del sistema Bruselas como constitutivas de derechos entre privados; he sugerido, no obstante, que otra lectura no es totalmente imposible, y que podría resultar oportuna. Es inevitable temer, a pocos días del final del período transitorio pactado con el Reino Unido para su salida ordenada de la Unión, y ante el cariz de las negociaciones ${ }^{105}$, que en un futuro próximo demandantes en la Unión serán blanco de medidas anti-suit en procesos sobre materias cubiertas por Reglamentos europeos. Una interpretación según la cual sí cabe leer en ellos - en algunas disposiciones- un derecho directamente exigible de una parte frente a la otra puede ser útil a fin de contrarrestar tales órdenes; y también, llegado el caso, para reforzar políticas legislativas con fuente en la Unión Europea, cuya efectividad aconseje que sean jueces de la Unión los que conozcan de litigios

\footnotetext{
${ }^{100}$ STJUE de 12 de diciembre de 2019, Aktiva Finants (C433/18, EU:C:2019:1074), apartado 29.

${ }^{101}$ STJUE de 15 de mayo de 1990, Hagen (C365/88, EU:C:1990:203), apartado 17, 19.

${ }^{102}$ STJUE de 15 de mayo de 1990, Hagen (C365/88, EU:C:1990:203), apartado 20; STJUE Turner, apartado 29.

${ }^{103}$ STJUE de 10 de febrero de 2009, Allianz y Generali Assicurazioni Generali (C185/07, EU:C:2009:69); apartados 24,

${ }^{104}$ Esto contrarresta también el argumento de la STJUE Turner, apartado 30, donde se había sostenido que la utilización de medidas anti-suit priva de eficacia a los mecanismos específicos previstos por el Convenio de Bruselas en caso de litispendencia y de conexidad.

${ }^{105}$ Este trabajo se ha cerrado el 12 de diciembre de 2020.
} $27,28$. 
en que tales políticas en juego. Paradójicamente, se da la razón de este modo a autores británicos, no especialmente pro-europeos, que en 2005 opinaron: "One wonders whether the antisuit-injunction of Common law systems is not something which other systems should adopt rather than something which English law should forget" ${ }^{106}$.

${ }^{106}$ B. Domann QC, A. Briggs, "Learning to learn from others in Europe in commercial litigation", en B. Bachman et al., Grenzüberschreitungen: Beiträge zum Internationalen Verfahrensrecht und zur Schiedsgerichtsbarkeit - Festschrift für Peter Schlosser zum 70. Geburtstag, pp. 161-173, p. 168. 